\title{
Empirical Study on the Effect of Environmental Factors on Enterprise Growth - Comparative Analysis of Chinese Large Scale Industrial Enterprises and Small/Medium Industrial Enterprises
}

\author{
Tao Guo ${ }^{1,2^{*}}$, Guangyi Wang ${ }^{1}$, Chen Wang ${ }^{1}$ \\ ${ }^{1}$ School of Economics and Management, Harbin Engineering University, Harbin Heilongjiang, CHINA \\ ${ }^{2}$ Enterprise Innovation Institute, Harbin Engineering University, Harbin Heilongjiang, CHINA
}

Received 11 June 2017 - Revised 13 August 2017 • Accepted 27 September 2017

\begin{abstract}
Based on resource dependence theory and organizational ecology by conducting literature review and theoretical analysis, we constructed an indicator system of how the growth of enterprises affects the regional environment. We selected large-scale industrial enterprises and small/medium industrial enterprises from 2007-2011 with five years of data from 29 provinces and cities in China to perform a comparative analysis. A correlation analysis shows that (1) natural resource \& infrastructure environment, business environment, human resource environment, social \& cultural environment, science \& technology environment, political environment have an influence on enterprise growth, but show some differences; and that (2) partial correlation and regression analysis show that natural resources \& infrastructure environment and business environment have a very significant impact on the results for the two types of enterprises. The human resource environment and social \& cultural environment have no significant impact on the results for the two types of enterprises. Science \& technology environment in large-scale industrial enterprises have a better positive impact than in small/medium industrial enterprises. In contrast, political environment in small/medium industrial enterprises have a better positive impact than in largescale industrial enterprises.
\end{abstract}

Keywords: regional environment, regional environmental indicator system, enterprise growth

\section{INTRODUCTION}

Many studies show that enterprise growth performance is affected by regional environments, which creates differences in the level of enterprise development in different regions. In China, India, and Brazil, such vast national and regional environmental differences and larger total country economies cause this situation to become more obvious.

A similar situation also exists in other countries. Pozoa et al. (2012) considered that hotel service industry enterprise growth is a factor that depends largely on labour costs and labour quality in a study comparing the Canary Islands and Madrid, Spain. Villaverde and Maza (2012) determined that foreign direct investment in Spain's 17 autonomous regions reflecting the FDI regional flows differences were quite obvious, and it also led to the development of a Spanish enterprise imbalance. Aritaa et al. (2002) compared American and Japanese semiconductor manufacturers spatial organization, concluding that regional environments for enterprise decision makers are an important guarantee for realizing benefit growth. Saxenian (1994) compared Silicon Valley and two hi-tech zones in the $128^{\text {th }}$ routeand determined that environment is the main factor of success in Silicon Valley. Other scholars have confirmed this phenomenon, see Tang (2006). 


\section{Contribution of this paper to the literature}

- Based on organizational ecology theory and resource dependence theory, by establishing an index system of regional environmental effects on enterprise growth,

- We select 29 cities with five years data from 2007 to 2011 to analyse the impact of regional environmental factors on Chinese enterprise growth and compare regional environmental factors on how differences affect SMEs and large enterprise growth.

- Regional environmental factors have a significant effect on enterprise growth. However, different regional environmental factors will create different growth performance effects on different sizes of enterprises.

Numerous empirical studies have shown that regional resources, local government management efficiency, regional innovation, regional culture and other factors influence enterprise, and become the important factors influencing enterprise growth performance in different regions. However, in a specific country for a period of time, how can one determine the impact of different regional environmental factors on business growth or whether the degree of regional environment factors on different types of enterprise has a similar influence?

This paper considers regional environments that affect enterprise growth performance as an indicator system, selects large scale industrial enterprise, small/medium industrial enterprise and regional environment factorrelated data of 29 provinces from 2007 to 2011 in China, and compares and analyses the data to explore this issue.

\section{THEORETICAL ANALYSIS}

\section{Formation of Regional Environment Differences}

Regional economics, economic geography, government intervention theory and other theories from different perspectives explain the formation of regional differences.

Regional economic theory discusse show production factors are not completely mobile or divisible, which causes regional differences as the inevitable result and natural phenomena of economic development (1984). Economic geography theory states that any two regions with natural resources, a resource structure, a developed history and other various aspects which determine their economic structure, will also exhibit formation conditions and economic development problems with key differences. Different stages of economic development for the area have a profound impact on the environment differences. Government intervention theory emphasizes how the policy burden of local governments and local government officials' promotion goals causes the formation of a "government grabbing hand" and "government supporting hand" (Shleifer and Vishny, 1994). Local governments, through local protectionism, subsidies, financial support and other means of intervention activity, affect the flow of capital, technology and labour.

\section{Influence of Environmental Factors on Enterprise Growth}

Regional environment includes the survival of enterprise growth boundaries (Nelson and Winter, 1982). Its impact on enterprise growth is mainly reflected in two aspects:

On the one hand, the regional environment provides the necessary resources for enterprise growth. Resources needed for enterprise growth cannot be fully met by its own production, and therefore must be obtained from other organizations or external organizations, which will cause a resource dependency (Pfeffer and Salancik, 1978). Availability of external resources can shape and constrain the choice of enterprise strategy and the development of companies; an adequate supply and competitiveness will be heavily dependent on the availability of external resources (Helfat and Peteraf, 2003). Within a particular area of enterprise, a considerable part of the resources needed for growth come from the regional environment, and thus the regional environment is a source of resources required for enterprise growth. Regional differences are an important source of growth differences in different regions.

On the other hand, regional environmental constraints can affect the enterprise's growth potential, growth path, growth process, and growth effect. An enterprise is an organic member of the business ecosystem and should systematically consider its dynamic relationship with the external environment (Moore, 1996). Based on organizational ecology research, on the macro level, environmental disturbances affect the organization's (enterprise's) established rate and mortality rate; on the micro level, the enterprise belongs to the environment and, due to the different degree of organizational dependence, the organization's activities and structure is also different. Thus, context-specific regions have an important influence on the new organization's (enterprise's) environmental choice for organizational evolution (enterprise growth), which plays a decisive role. 


\section{THEORETICAL MODEL AND INDEX SYSTEM}

\section{Regional Division of Environmental Factors}

There are various ways that scholars have divided regional environmental factors. Banai and Wakolbinger (2011), based on the perspective of regional economy, divide the regional environment into economic, infrastructure, quality of life and socio-economic aspects. Rubalcaba and Gago (2003), by studying 51 major cities in 12 European countries, established a business service index system with regional environment, regional environment including resource endowments, infrastructure, cultural social environment, and regional reputation factors. Malinowski (2012), based on comprehensive development indicators, divided regional environmental factors into six areas, including technical infrastructure, social infrastructure, economic potential, social potential, living standards and environmental protection, then broke them down into 48 indicators. Lasch (2011), studying regional environment supporting entrepreneurship, and based on the perspective of supply and demand, divides regional environment into supply perspective including human capital, social capital and unemployment, demand perspective including infrastructure, industry structure and aggregation. $\mathrm{Xu}$ et al. (2011) divide regional environment into four areas, including regional production factors, regional industry factors, regional soft environment and regional brands. In addition, other scholars divide regional environment into regional soft environment and regional hard environment, the former reflects the natural environment, infrastructure and human resource, etc., while the latter reflects the competitive system and culture, such as government, legal, business and other aspects (2007).

A comprehensive view of scholars shows that regional environmental factors can be summarized to include six areas consisting of natural resource and infrastructure environments, human resource environments, science and technology environments, business environments, political environments, and social and cultural environments. In this paper, we build a regional environment indicator system which reflect show regional environments affect enterprise growth in these six areas.

\section{Regional Environment Factors Influence on Enterprise Growth Performance}

\section{Natural resource $\mathcal{E}$ infrastructure environment}

Natural resources (including energy) and infrastructure levels are the basic guarantee of enterprise development (Wang, 2016). When a region is able to provide abundant and cheap natural resources, enterprise can use local materials, saving costs and time, which in turn improve enterprise performance. The more convenient regional transportation is, the smoother exchanges of information will be, which is better for enterprises engaged in innovative activities and favourable for regional innovation output. Relevant data from 95 countries and more than 72,000 companies shows that improving infrastructure environments can improve output and productivity, thus promoting enterprise growth (Carlin et al., 2010). At the same time, enterprise growth and development must limit environmental carrying capacity.

\section{Human resource environment}

Talent has become an increasingly important strategic resource. Regional human resource development has become one of the key factors of core competitive power for enterprise. Enterprise operations, the supply of human resource development and their external environment are closely related to skilled workers, technicians and managers' restrictions on the enterprise's management and development. Geographic distribution of universities, undergraduate and graduate students graduating each year and staff education have an impact on the amount of new enterprise, access to knowledge and human resource location for knowledge-based businesses (Baptista and Mendonca, 2010).

\section{Science E technology environment}

Science and technology environments are a collection of enterprise social environments in which technological factors and various factors are directly related. The innovation environment of science and technology can promote the introduction of external innovation resources, cooperative $R \& D$ and the introduction of scientific and technological talents, which is conducive to creating new learning environments and promoting the improvement of technical enterprise capabilities (Nobel \& Birkinshaw, 1998). Regional science and technology research institutions, science and technology funding, universities and other departments directly affect the amount of enterprise science and technology activity, activity frequency and development levels. 


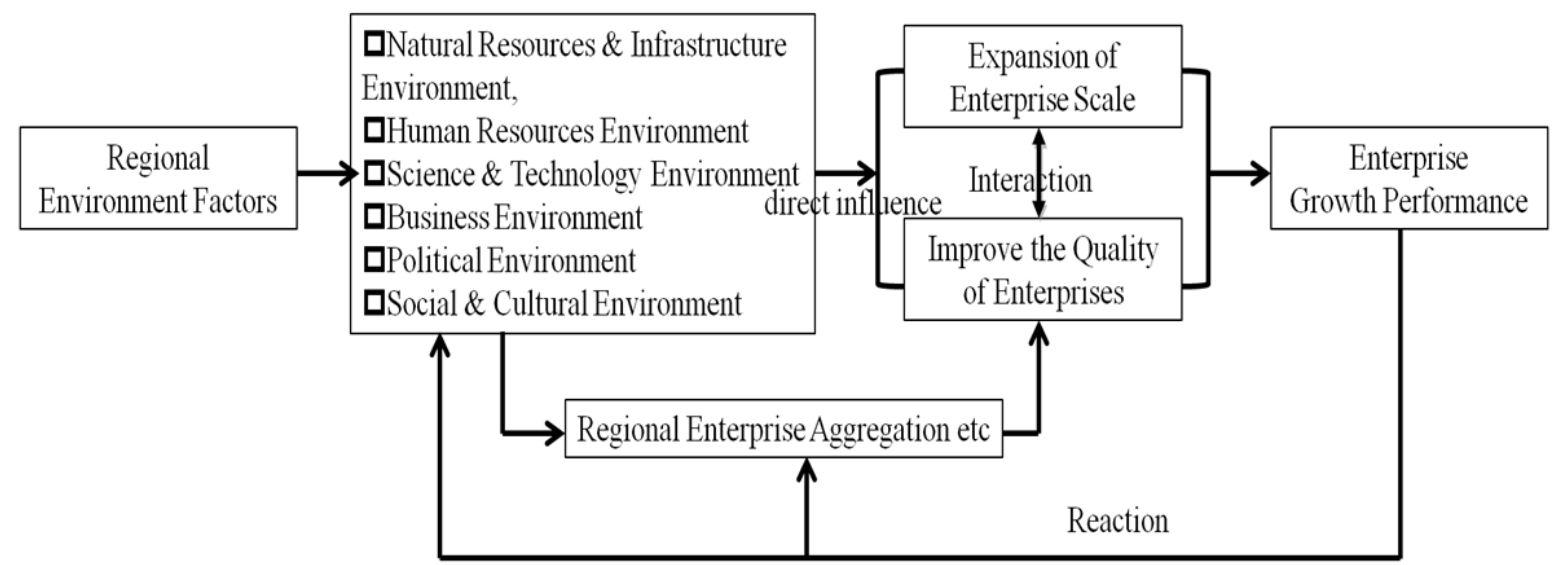

Figure 1. Regional environment factors influence on enterprise growth performance

\section{Business environment}

The market is the balance of enterprise activity. In this public platform, goods and services can flow freely, which is critical for enterprise growth. Market openness, specialization and market dynamics have a direct impact on enterprise growth (Liu, 2016). The acquisition of funds required for enterprise growth depends on the regional financing environment, and the regional entrepreneurial environment is the soil for new enterprises to develop and grow. Improving the financial service system can provide adequate funds for an enterprise, reduce costs and promote faster enterprise growth (Beck, 2003).

\section{Political environment}

The high quality of the operational efficiency and work style of the government can reduce transaction costs and improve operating efficiency. Government policy development and implementation can effectively support innovation activities. Government procurement can encourage enterprises to develop new products and new technologies. Empirical studies have shown that the effectiveness of legal institutions and corporate performance are related (Beck, 2006). Legal systems, by reducing business risks, affect enterprise performance. With the improvement of the legal system quality, the enterprise performance will increase (Laeyen, 2007).

\section{Social \& cultural environment}

Regional social and cultural environment affect the company's management system, management efficiency, employment mechanism and corporate culture (Tang, 2006; Fan, 2007). It can also affect the success of entrepreneurs and employees desire, spirit of innovation, decision-making ability, market awareness and market development capability, ultimately affecting growth performance. During analysis, we propose regional environment factors affecting the performance of enterprise growth theory models (see Figure 1).

\section{Construction of Regional Environment Affects Enterprise Growth Index System}

According to the previous analysis, for natural resource and infrastructure environments we select nine indicators, for human resource environments we select eight indicators, for science and technology environments we select seven indicators, for business environments we select nine indicators, for political environments we select eight indicators, and for social and cultural environments we select six indicators. It is worth noting that (1) Taking into account that scientific and technological talents have been embodied in human resources environments, science and technology environment indicators are not included in talent category. (2) In research on the culture and enterprise growth, some scholars such as Cox (1993), Hoffman (1959) and Alderfer (1982) have performed studies that are embodied in the cultural forces (diversity) for working groups or individual members preferences shaping force; other scholars, such as Lu and Zhang (2006), who focus on enterprise culture, offer their own soft power performance. For enterprise culture, research on regional cultural differences in enterprise growth is still currently in the exploratory stage. Relevant data it is difficult to identify and capture from the available Yearbook information. Therefore, based on the diameter uniformity of data considered in this paper, we simply made use of the regional cultural development level to set the regional environment indicators. 
Table 1. Indicator system of regional environment and enterprise growth

\begin{tabular}{|c|c|}
\hline Variable(Code) & Measure codes and corresponding items(unit) \\
\hline \multirow{9}{*}{$\begin{array}{c}\text { Natural resource \& } \\
\text { infrastructure } \\
\text { environment } \\
(E v 1)\end{array}$} & $\mathrm{X}_{01}$ Total amount of water resources (billion cubic metres) \\
\hline & $X_{02}$ Annual mining volume of non-oil \& gas resources (ten thousand tons) \\
\hline & $\mathrm{X}_{03}$ Electric power consumption (million kilowatt hours) \\
\hline & $\mathrm{X}_{04}$ Waste emissions (ten thousand tons) \\
\hline & $\mathrm{X}_{05}$ Industrial pollution abatement investment (ten thousand RMB) \\
\hline & $\underline{X}_{06}$ Transport of goods flow ability (million tons $/ \mathrm{km}$ ) \\
\hline & $\mathrm{X}_{07}$ Internet access number (ten thousand people) \\
\hline & $X_{08}$ Mobile phone and fixed phone users (ten thousands of families) \\
\hline & $\mathrm{X}_{09}$ The penetration rate of urban water \&gas supply (\%) \\
\hline \multirow{8}{*}{$\begin{array}{l}\text { Human resource } \\
\text { environment } \\
\text { (Ev2) }\end{array}$} & $X_{10}$ The end of the registration number of the urban employment (ten thousand people) \\
\hline & $\mathrm{X}_{11}$ The registered urban unemployment rate (\%) \\
\hline & $X_{12}$ The number of registered job-seekers (ten thousand people) \\
\hline & $X_{13}$ The number of graduates in technical schools (person) \\
\hline & $\underline{\mathrm{X}_{14} \text { Labour productivity }(\%)}$ \\
\hline & $X_{15}$ The share of employed persons who graduated from high school (\%) \\
\hline & $X_{16}$ Vocational skills appraisal was issued by the agency(person) \\
\hline & $\mathrm{X}_{17}$ Employment in job training centre and vocational training (person) \\
\hline \multirow{7}{*}{$\begin{array}{l}\text { Science \&technology } \\
\text { environment (Ev3) }\end{array}$} & $\mathrm{X}_{18}$ The number of research institutions and universities(unit) \\
\hline & $\mathrm{X}_{19} \mathrm{R} \& \mathrm{D}$ issue number (item) \\
\hline & $\mathrm{X}_{20} \mathrm{R} \& \mathrm{D}$ funding by internal expenditures (ten thousand $\mathrm{RMB}$ ) \\
\hline & $\begin{array}{l}\mathrm{X}_{21} \text { Experimental development project expenditures accounted for R \& D institutions, universities R \& D internal } \\
\text { expenditures proportion (\%) }\end{array}$ \\
\hline & $\underline{X_{22}}$ The number of published scientific papers(articles) \\
\hline & $\mathrm{X}_{23}$ The patent number(piece) \\
\hline & $\mathrm{X}_{24}$ Technical market turnover (ten thousand RMB) \\
\hline \multirow{9}{*}{$\begin{array}{l}\text { Business environment } \\
\qquad(E v 4)\end{array}$} & $\underline{X}_{25}$ The total retail sales of social consumer goods (billion RMB) \\
\hline & $\underline{\mathrm{X}_{26} \text { Billion commodity trading market turnover (billion RMB) }}$ \\
\hline & $\mathrm{X}_{27}$ The total foreign business investment (ten thousand USD) \\
\hline & $\underline{X_{28} \text { Financial services institutions (unit) }}$ \\
\hline & $\mathrm{X}_{29}$ The amount of loans provided by the banking financial institutions (billion RMB) \\
\hline & $\underline{X}_{30}$ The total transaction amount of bonds in Shenzhen Stock Exchange \& Shanghai Stock Exchange (billion RMB) \\
\hline & $X_{31}$ The number of private businesses (ten thousands of families) \\
\hline & $\mathrm{X}_{32}$ Venture capital intensity (ten thousand RMB) \\
\hline & $\mathrm{X}_{33}$ The rate of private industrial output value accounted for the proportion of region GDP (\%) \\
\hline \multirow{8}{*}{$\begin{array}{l}\text { Political environment } \\
\qquad \text { (Ev5) }\end{array}$} & $\mathrm{X}_{34}$ The amount of export tax rebates income in tax revenue (ten thousand RMB) \\
\hline & $\mathrm{X}_{35}$ Government fiscal expenditure in social security (billion RMB) \\
\hline & $\mathrm{X}_{36}$ Government fiscal expenditure in public services (billion RMB) \\
\hline & $\mathrm{X}_{37}$ Government fiscal expenditure in public security (billion RMB) \\
\hline & $\underline{X}_{38}$ Received an application for administrative reconsideration cases (case) \\
\hline & $\underline{X_{39} \text { Administrative litigation case acceptance (case) }}$ \\
\hline & $\mathrm{X}_{40}$ Labour disputes settlement rate (\%) \\
\hline & $\mathrm{X}_{41}$ Patent department dealing with infringement cases settlement rate (\%) \\
\hline \multirow{6}{*}{$\begin{array}{l}\text { Social \&cultural } \\
\text { environment } \\
\text { (EvG) }\end{array}$} & $\mathrm{X}_{42}$ The number of employees in the cultural market agency (person) \\
\hline & $\mathrm{X}_{43}$ Culture completed infrastructure investment (ten thousand RMB) \\
\hline & $\mathrm{X}_{44}$ The publication of books, periodicals and newspapers (billion copies) \\
\hline & $\mathrm{X}_{45}$ The publication of audio, video products (ten thousand boxes/pieces) \\
\hline & $\mathrm{X}_{46}$ The total circulation visitors of public library (ten thousand people) \\
\hline & $\mathrm{X}_{47}$ The visitors for museum displays, exhibition (thousand people) \\
\hline \multirow{7}{*}{$\begin{array}{l}\text { Enterprise growth } \\
\quad(E t 1 \& 2)\end{array}$} & $\underline{Y_{01} \text { Output value (billion RMB) }}$ \\
\hline & $\underline{\mathrm{Y}_{02} \text { Profit (billion RMB) }}$ \\
\hline & $\mathrm{Y}_{03}$ Main business income (billion RMB) \\
\hline & $Y_{04}$ The number of employees (ten thousand people) \\
\hline & $\underline{Y_{05} \text { The total assets growth rate (\%) }}$ \\
\hline & $Y_{06}$ The main business income growth rate (\%) \\
\hline & $Y_{07}$ The profit growth rate (\%) \\
\hline
\end{tabular}

Regarding enterprise growth measurement, we focused on expansion of the enterprise scale and enterprise growth trend in two ways. In this paper, according to the common measure indicators, we divided expansion of the enterprise scale into output value, profit, main business income and the number of employees. We divided enterprise growth trends into the total assets growth rate, the main business income growth rate and the profit growth rate. These are combined with the above analysis and take the evaluation of scientific, operational, independence and simplicity aspects into account. In this paper, we establishment regional factors that affect the enterprise growth index system (see Table 1). 
Table 2. Explanation and sources for section indicators

\begin{tabular}{cl}
\hline Part index code & Description and source \\
\hline$X_{02}$ & This index data is from the "China Land and Resources Statistical Yearbook". \\
\hline$X_{04}$ & To unify index units and waste emissions in each region, we analyse eight after-industrial emissions. \\
\hline$X_{14}-X_{13}, X_{15}-X_{17}, X_{40}$ & This index data is from the "China Labour Statistical Yearbook". \\
& $\begin{array}{l}\text { Reference Lee made up in the "Nankai Economic Studies 2011 (2)" in the research methods, } \\
\text { references related formula } B=Y / L \text {. Where: B for labour productivity; } Y \text { represents the average years } \\
\text { of schooling; } L \text { is for per capita GDP logarithms. }\end{array}$ \\
\hline $\begin{array}{l}\text { Regional financial services institutions including: commercial banks, policy banks, credit unions, postal } \\
\text { savings shop, financial asset management companies, trust and financial companies, financial leasing } \\
\text { companies, loan companies, monetary economics, and other financial institutions, and so on. The } \\
\text { index data from the China Banking Regulatory Commission's website, statistics deadline: 2014.03.05. }\end{array}$ \\
\hline$X_{28}$ & $\begin{array}{l}\text { This index data is from the "China Financial Yearbook". } \\
\text { Exchange Statistical Yearbook". }\end{array}$ \\
\hline$X_{30}$ & $\begin{array}{l}\text { This index data is from the "China Venture Capital Report". } \\
\text { This index data is from the "China Tax Yearbook." Liaoning data includes Dalian, Zhejiang data } \\
\text { includes Ningbo, Fujian data includes Xiamen, Shandong data includes Qingdao, Guangdong data } \\
\text { includes Shenzhen. }\end{array}$ \\
\hline$X_{34}-X_{39}$ & This index data is from the "China Law Yearbook". \\
\hline$X_{41}$ & $\begin{array}{l}\text { The index data is from the Chinese State Intellectual Property Office website, statistics deadline: } \\
\text { 2014.03.05. }\end{array}$ \\
\hline$X_{42}-X_{43}, X_{46}-X_{47}$ & This index data is from the "Chinese cultural heritage Statistical Yearbook ". \\
\hline
\end{tabular}

$\mathrm{X}_{42}-\mathrm{X}_{43}, \mathrm{X}_{46}-\mathrm{X}_{47} \quad$ This index data is from the "Chinese cultural heritage Statistical Yearbook"

Note: For missing data, such as $X_{32}$, we use annual data. Since this paper analyses the weight of each index value, this substitution does not affect the analysis results by a large extent.

\section{EMPIRICAL ANALYSIS}

\section{Data Sources and Description}

We selected the statistical data from 29 provinces (in addition to Tibet, Xinjiang, Hong Kong, Macao, Taiwan) for analysing. It is worth noting: (1) Our selected data mostly comes from the "China Statistics Yearbook" and "China Technology Statistics Yearbook", enterprise growth related data come from "China SMEs Yearbook" and "China Industrial Economic Statistics Yearbook", other data sources are shown in Table 2. (2) Taking into account the lagged effects of some indicators in time and space, this paper chooses five years from 2007 to 2011 for analysis. (3) Because data for Tibet, Xinjiang is missing in many aspects, it is not considered in our study. (4) In empirical research, regional environmental factors and type of business code are used as reference (5) In the analysis results, small/medium industrial enterprises are referred to as SMEs, and large scale industrial enterprises are referred to as large enterprises.

\section{Exploratory Factor Analysis}

Before data processing, negative indicators (such as $\mathrm{X}_{04}, \mathrm{X}_{11}$ ) must be dealt with by positive treatment and all indicators are standardized. We used SPSS software to address the exploratory factor analysis of variables. Table 3 shows the results of the exploratory factor analysis. Among the results, the Ev1 measurement scale reliability Cronbach's a value is 0.960 , which shows good internal reliability of the system. The KMO value is 0.799 ; the factor limit of the factor analysis is exceeded, indicating that the number of samples is sufficient. Bartlett's Test value is $807.457(p<0.01)$, indicating that each item is interrelated and suitable for factor analysis. Using the method of principal components factor analysis, factor rotation techniques using maximum variance, we extract three common factors (see Table 3), which reflect the level of energy consumption, environmental protection and communication. The cumulative variance contribution rate is $99.244 \%$, indicating that $99.244 \%$ can be explained by the extracted common factor, which is sufficient to describe Ev1.According to this method; we can obtain the other five regional environments. The validity (Cronbach's a value), KMO value and Bartlett's Test value all meet the requirements (see Table 3 ). 
Table 3. Summary of the exploratory factor analysis

\begin{tabular}{|c|c|c|c|c|c|}
\hline Variable & Extraction factor & $\begin{array}{l}\text { Cumulative variance } \\
\text { contribution rate (\%) }\end{array}$ & $\begin{array}{c}\text { Validity } \\
\text { (Cronbach's } \alpha) \\
\end{array}$ & KMO value & Bartlett's test \\
\hline \multirow{3}{*}{ Ev1 } & Energy consumption & \multirow{3}{*}{99.244} & \multirow{3}{*}{0.960} & \multirow{3}{*}{0.799} & \multirow{3}{*}{$\begin{array}{c}807.457 \\
(p=0.000<0.01)\end{array}$} \\
\hline & Environmental protection & & & & \\
\hline & Communication level & & & & \\
\hline \multirow{2}{*}{ Ev2 } & Employment situation & \multirow{2}{*}{91.748} & \multirow{2}{*}{0.923} & \multirow{2}{*}{0.819} & 493.725 \\
\hline & Social labour supply & & & & $(p=0.000<0.01)$ \\
\hline \multirow[b]{2}{*}{ Ev3 } & Technology foundation & \multirow{2}{*}{89.713} & \multirow{2}{*}{0.931} & \multirow{2}{*}{0.730} & 1167.227 \\
\hline & Technology investment & & & & $(p=0.000<0.01)$ \\
\hline \multirow{3}{*}{ Ev4 } & Market activity & \multirow{3}{*}{89.909} & \multirow{3}{*}{0.930} & \multirow{3}{*}{0.782} & \\
\hline & Entrepreneurial atmosphere & & & & $\begin{array}{c}1531.137 \\
(n-0000<001)\end{array}$ \\
\hline & Financing supportive & & & & \\
\hline \multirow{2}{*}{ Ev5 } & Social legal construction & \multirow{2}{*}{85.056} & \multirow{2}{*}{0.918} & \multirow{2}{*}{0.748} & 932.546 \\
\hline & Government support & & & & $(p=0.000<0.01)$ \\
\hline \multirow{3}{*}{ Ev6 } & Cultural foundation & \multirow{3}{*}{84.042} & \multirow{3}{*}{0.856} & \multirow{3}{*}{0.791} & \\
\hline & Cultural creation & & & & $\begin{array}{c}438.484 \\
(n=0.000<0.01)\end{array}$ \\
\hline & Cultural transmission & & & & \\
\hline \multirow{2}{*}{ Et } & Expansion of enterprise scale & \multirow{2}{*}{98.435} & \multirow{2}{*}{0.984} & \multirow{2}{*}{0.722} & 1697.150 \\
\hline & Enterprise growth trend & & & & $(p=0.000<0.01)$ \\
\hline
\end{tabular}

Note: Factor analysis was extracted using principal component analysis. The rotation technique is the largest variance orthogonal rotation method. Factor loading matrix coefficients in absolute value refer to the view of Hair (1992) set to 0.6.

Table 4. Partial correlation analysis

\begin{tabular}{|c|c|c|c|c|}
\hline Enterprise type & Partial correlation analysis & Control variables & Correlation & Two-tailed test \\
\hline \multirow{6}{*}{$\begin{array}{c}\text { SMES } \\
(E t 1)\end{array}$} & Ev1 $\rightarrow$ Et1 & Ev2, other 5 environment variables & 0.438 & 0.000 \\
\hline & $E v 2 \rightarrow E t 1$ & $E v 3$, other 5 environment variables & 0.130 & 0.126 \\
\hline & Ev3 $\rightarrow$ Et1 & Ev4, other 5 environment variables & -0.053 & 0.531 \\
\hline & $E v 4 \rightarrow E t 1$ & Ev5, other 5 environment variables & 0.446 & 0.000 \\
\hline & $E v 5 \rightarrow E t 1$ & Ev6, other 5 environment variables & 0.448 & 0.000 \\
\hline & $E v 6 \rightarrow E t 1$ & Ev1, other 5 environment variables & 0.097 & 0.255 \\
\hline \multirow{6}{*}{$\begin{array}{l}\text { Large Enterprise } \\
\quad(E t 2)\end{array}$} & $E v 1 \rightarrow E t 2$ & Ev2, other 5 environment variables & 0.650 & 0.000 \\
\hline & $E v 2 \rightarrow E t 2$ & $E v 3$, other 5 environment variables & 0.150 & 0.076 \\
\hline & $E v 3 \rightarrow E t 2$ & Ev4, other 5 environment variables & 0.242 & 0.004 \\
\hline & $E v 4 \rightarrow E t 2$ & Ev5, other 5 environment variables & 0.354 & 0.000 \\
\hline & $E v 5 \rightarrow E t 2$ & Ev6, other 5 environment variables & 0.199 & 0.018 \\
\hline & $E v 6 \rightarrow E t 2$ & Ev1, other 5 environment variables & -0.217 & 0.110 \\
\hline
\end{tabular}

Notes: $+p<0.1,{ }^{*} p<0.05,{ }^{* *} p<0.01,{ }^{* * *} p<0.001$.

\section{Correlation Analysis}

Partial correlation analysis (see Table 4 ) shows that

(1) For Et1, the correlation coefficient between Ev2 and Et1, Ev3 and Et1, Ev6 and Et1 are 0.130, -0.053, 0.097, respectively under the other five controlled variables, indicating that excluding the above five environmental variables $E v 2$ to $E t 1, E v 3$ to $E t 1$, and $E v 6$ to $E t 1$ show a negative correlation and the two-tailed testis not significant, which means that Ev2, Ev3, and Ev6 have no effect on Et1 growth. This indirect description of Ev2, Ev3, and Ev6 requires coordination with other regional environment in order to highlight the importance of Et1 growth. From the correlation coefficient, Ev2 is more dependent on the other environments than Ev3 and Ev6. The correlation coefficient between Ev1 and Et1,Ev4 and Et1,Ev5 and Et1 are 0.438, 0.446, 0.448, respectively, under the other five controlled variables, indicating that excluding the above five environmental variables Ev1 to Et1, Ev4 to Et1, Ev5 to Et1 shows a positive correlation and the two-tailed test is significant under $0.1 \%$ significant level, which means that Ev1,Ev4, Ev5 have a significant positive effect on Et1 growth.

(2) For $E t 2$, the correlation coefficient between $E v 6$ and $E t 2$ is -0.217 when the other five variables are controlled, indicating that excluding the above five environmental variables, Ev6 to Et2 shows a negative correlation and the two-tailed test is not significant, which means that Ev6 has no effect on Et2 growth. This indirect description of Ev6 requires coordination with other regional environments in order to highlight the importance of Et 2 growth. The correlation coefficient between $E v 1$ and $E t 2, E v 3$ and $E t 2, E v 4$ and $E t 2$ are 0.650, 0.242, 0.354, respectively, under the other five controlled variables, indicating that excluding the above five environmental variables Ev1 to Et2, Ev3 to 
Table 5. Regression Analysis

\begin{tabular}{|c|c|c|c|c|c|c|c|c|}
\hline & \multicolumn{4}{|c|}{ Model: 1SEMs(Et1) } & \multicolumn{4}{|c|}{ Model 2: Large Enterprises(Et2) } \\
\hline & \multicolumn{2}{|c|}{$\begin{array}{c}\text { Non-Standardized } \\
\text { Coefficient }\end{array}$} & \multirow[t]{2}{*}{ Beta } & \multirow[t]{2}{*}{ VIF } & \multicolumn{2}{|c|}{$\begin{array}{l}\text { Non-Standardized } \\
\text { Coefficient }\end{array}$} & \multirow[t]{2}{*}{ Beta } & \multirow[t]{2}{*}{ VIF } \\
\hline & B (Est. V) & SE & & & B (Est. V) & SE & & \\
\hline Ev1 & 0.114 & 0.020 & $\begin{array}{l}0.291^{* * *} \\
(5.724)\end{array}$ & 2.750 & 0.099 & 0.010 & $\begin{array}{l}0.600^{* \star *} \\
(10.049)\end{array}$ & 2.750 \\
\hline Ev2 & 0.010 & 0.006 & $\begin{array}{c}0.082 \\
(1.539)\end{array}$ & 3.044 & 0.006 & 0.003 & $\begin{array}{c}0.112 \\
(1.787)\end{array}$ & 3.044 \\
\hline Ev3 & 0.000 & 0.000 & $\begin{array}{l}-0.025 \\
(-0.628) \\
\end{array}$ & 1.744 & 0.001 & 0.000 & $\begin{array}{l}0.140^{* *} \\
(2.933)\end{array}$ & 1.744 \\
\hline Ev4 & 0.035 & 0.006 & $\begin{array}{l}0.321^{*+* t} \\
(5.853)\end{array}$ & 3.206 & 0.013 & 0.003 & $\begin{array}{l}0.287^{* \star \star} \\
(4.445) \\
\end{array}$ & 3.206 \\
\hline Ev5 & 0.004 & 0.001 & $\begin{array}{l}0.330^{* * *} \\
(5.892)\end{array}$ & 3.346 & 0.001 & 0.000 & $\begin{array}{c}0.158 \\
(2.390)\end{array}$ & 3.346 \\
\hline Ev6 & 0.048 & 0.042 & $\begin{array}{c}0.076 \\
(1.143) \\
\end{array}$ & 4.697 & -0.055 & 0.021 & $\begin{array}{c}-0.204 \\
(-2.617) \\
\end{array}$ & 4.697 \\
\hline$R^{2}$ & \multicolumn{4}{|c|}{0.871} & \multicolumn{4}{|c|}{0.821} \\
\hline $\operatorname{Adj}^{2}$ & \multicolumn{4}{|c|}{0.865} & \multicolumn{4}{|c|}{0.813} \\
\hline$F$ & \multicolumn{4}{|c|}{$154.692^{\star * \star}$} & \multicolumn{4}{|c|}{$105.401^{* \star \star}$} \\
\hline$N$ & \multicolumn{4}{|c|}{145} & \multicolumn{4}{|c|}{145} \\
\hline$D-W$ & \multicolumn{4}{|c|}{1.700} & \multicolumn{4}{|c|}{2.145} \\
\hline
\end{tabular}

Notes: ${ }^{*} p<0.05,{ }^{* *} p<0.01,{ }^{* * *} p<0.001, T$ value in parentheses.

Table 6. The effects of environmental factors on different types of enterprise

\begin{tabular}{ccccccc}
\hline & Ev1 & Ev2 & Ev3 & Ev4 & Ev5 & Ev6 \\
\hline$E t 1$ & $\bullet$ & $O$ & $O$ & $\bullet$ & 0 & 0 \\
\hline$E t 2$ & $\bullet$ & 0 & 0 & $\bullet$ & 0 & 0 \\
\hline
\end{tabular}

\section{Source: Authors.}

Notes: • Very significant, () Relative significant, $\bigcirc$ No significant.

$E t 2$, and Ev4 to Et2 show a positive correlation, and the two-tailed test is significant under a $0.1 \%$ significant level, which means that Ev1, Ev3, and Ev4 have a significant positive effect on Et2 growth. The correlation coefficient between Ev2 and Et2 is 0.150 under the other five controlled variables, indicating that excluding the above five environmental variables, Ev2 to Et2 shows a positive correlation and the two-tailed test is significant under the $10 \%$ significant level, which means that Ev2 has a significant negative effect on Et2 growth. The correlation coefficient between Ev5 and Et2 is 0.199 under the other five controlled variables, indicating that excluding the above five environmental variables, Ev5 to Et2, shows a positive correlation and the two-tailed test is significant under $5 \%$ significant level, which means that Ev5 has a significant negative effect on Et2 growth.

\section{Regression Analysis}

According to the above discussion, we established the following model:

$$
\text { growth }_{i t}=\beta_{0}+\beta_{1} E v 1_{i t}+\beta_{2} E v 2_{i t}+\beta_{3} E v 3_{i t}+\beta_{4} E v_{i t}+\beta_{5} E v 5_{i t}+\beta_{6} E v 6_{i t}+\varepsilon_{i t}
$$

Among them, $\varepsilon_{i t}$ is a residual, variable subscription, $i$ and $t$ represent $1-29$ provinces and municipalities and 2007-2011, respectively. From Table 6, according to the results of the regression analysis, we find that (see Table 5)

(1) Model 1 and Model 2 have a strong explaining power and the adjusted goodness of the model fit also has a good effect. All of the index information in the target dependent variable can be explained by $86.5 \%$ and $81.3 \%$. The F-test and D-W test all approve. The variance inflation factor (VIF) value in both models is less than 5; indicating that a multi-collinearity problem does not exist between the variables.

(2) In model 1, there is a significant positive linear correlation between Ev1 and Et1, Ev4 and Et1, Ev5 and Et1 under $0.1 \%$ significance level. This means that Ev1 to Et1, Ev4 to Et1, Ev5 to Et1 have a significant positive effect on $E t 1$ growth. In addition, there is no linear correlation between Ev2 and Et1, Ev 3 and Et1, Ev 6 and Et1, which means that $E v 2$ to $E t 1, E v 3$ to $E t 1$, and Ev6 to Et1 have no effect on Et1 growth. In model 2, there is a significant positive linear correlation between $E v 1$ and $E t 2, E v 4$ and $E t 2$ under a $0.1 \%$ significance level. This means that Ev1 to Et2, Ev4 to $E t 2$ have a significant positive effect on Et2 growth. There is a significant positive linear correlation between Ev3 and $E t 2$ under a $1 \%$ significance level. This means that $E v 3$ to $E t 2$ has a significant positive effect on $E t 2$ growth. In addition, there is no linear correlation between $E v 2$ and $E t 2, E v 5$ and $E t 2, E v 6$ and $E t 2$, which means that Ev2 to Et2, Ev5 to Et2, and Ev6 to Et2 has no effect on Et1 growth. 
(3) Comparison of model 1 and model 2: There is a significant positive linear relationship between Ev1, Ev4 and Et1,Ev1, Ev4 and Et2 in both model 1 and model 2 under a 0.1\% significance level. This means both Ev1 and Ev4 have a significant positive effect on Et1 and Et2 growth. There is no linear relationship between Ev2, Ev6 and Et1, Ev2, Ev6 and Et2 in both model 1 and model 2. This means that Ev2 and Ev6 both have no effect on Et1 and Et2 growth. Compared with model 1, Ev3 in model 2 has a significant positive effect on Et2 growth, which is better than Et1 growth. Compared with model 2, Ev5 in model 1 has a significant positive effect on Et1 growth, which is better than Et2 growth.

\section{EMPIRICAL ANALYSIS}

\section{Comprehensive Description of the Empirical Results}

To examine the impact of the interaction between variables, we use partial correlation processing of data to analyse the different effects of the regional environmental factors on two types of enterprise under the control of the other five environmental variable conditions. Partial correlation analysis results indicate that Et1,Ev1,Ev4, and Ev5 have a significant promoting role in Et1 growth performance. Meanwhile, Ev2, Ev3, and Ev6 have no effect on Et1 growth. For Et2, in addition to Ev6 having no effect on $E t 2$ growth, Ev1, Ev2, Ev3, Ev4, and Ev5 have a significant promoting role in Et2 growth performance. Furthermore, based on partial correlation analysis, we use regression analysis to reveal six regional environmental factors that affect the different influence degree on the two types of enterprise growth. The empirical results show that regional environment has an impact on enterprise growth, but the effect of different types of enterprise growth is different. Specifically, Ev1 and Ev4 both have a significant promoting role in $E t 1$ and $E t 2$ growth performance. In addition, Ev2 and Ev5 have no effect on Et1 and Et2 growth. Importantly, Ev3 in Et2 has a better positive impact than Et1, Ev5 in Et1 has a better positive impact than Et2 (see Table 6).

\section{The Impact of Environmental Factors on the Regional Enterprise Growth Analysis}

(1) Natural resource \& infrastructure environment as well as business environment both have a very significant influence on SMEs and large enterprise growth.

In natural resource \& infrastructure environment, energy consumption, environmental protection, and communication levels have an influence effect on two types of enterprise, and the results are very obvious. The elements of nature output still play an important role in enterprise whether for SMEs or large enterprise. In business environment, market activity, entrepreneurial atmosphere, and financing support have a significant impact effect on the two types of enterprise. This point agrees with other scholars ( $\mathrm{Lv}$ and $\mathrm{Su}, 2008)$. However, it is worth noting that bank loans are still the main source of enterprise funding in China, and the proportion of stocks or bonds financing is still small. In addition, China's capital market is still underdeveloped, market potential is not fully developed, and the leading role of indirect financing needs further strengthening. Thus, although improving business environments can promote enterprise growth, the benefit is still low for SMEs.

(2) Human resource environment as well as social \& cultural environment both have no significant influence on SMEs or large enterprise growth.

In human resource environment, employment situations and social labour supply both have no significant impact on the two types of enterprises. The "Governance, Investment Environment, and Harmonious Society -120 cities' competitiveness improving in China" research report (World Bank, 2006) shows that while there is a lack of well-trained and highly skilled personnel in the southeast region, it benefits from appropriate policies and developed rapidly in areas where there is no good human resource endowment. Additionally, education and technology in the northeast and northwest have a relative development lag. The results of this study show that this situation has not improved significantly in the five years between 2007 and 2011. In social culture environment, cultural foundation, cultural creation, and cultural transmissions have no significant impact on the two types of enterprise. This indicates that the current level of regional cultural development does not produce effective impacts on enterprise growth in China. Due to data availability, this paper does not address the regional effect of cultural differences on enterprise growth.

(3) Science \& technology environment as well as political environment have different impacts on large enterprise and SMEs.

For large enterprises in science \& technology environment, technology foundations and technology investments have a very significant influence on large enterprise, more than on SMEs. This agrees with other scholars' opinions (Sorensen and Stuart, 2000). However, our results still show that in China, SMEs still face the grim reality of a shortage of innovative power and creativity. In political environment, social legal construction and government 
support have greater impact on SMEs. The results of this study show that for growth of SMEs, the role of the market mechanism is still far from sufficient.

\section{CONCLUSIONS AND LIMITATIONS}

Based on organizational ecology theory and resource dependence theory, by establishing an index system of regional environmental effects on enterprise growth, we select 29 cities with five years data from 2007 to 2011 to analyse the impact of environmental factors on Chinese enterprise growth and compare regional environmental factors on how differences affect SMEs and large enterprise growth. We find that regional environmental factors have a significant effect on enterprise growth. However, different regional environmental factors will create different growth performance effects on different sizes of enterprises.

The limitations of this paper are as follows. First, our study only focuses on the one-way effect of environmental factors on enterprise growth, and does not involve any interaction between regional environmental impacts on enterprise growth. Moreover, the mechanism for regional environmental factors that affect enterprise growth has not been intensively studied. Second, limited by space and data availability, this paper discusses regional environmental factors affecting different sizes of enterprises growth in a relatively macroscopic statistical analysis. We have not yet researched enterprises of different ownership and in different industries. Finally, we are still limited by data availability, and the paper's focus on regional cultural indicators only reflects the level of development to regional culture, failing to reflect regional cultural differences. This shortfall will be further improved in future studies.

\section{FUND SUPPORT}

(1) National Social Science Fund Project (11CGL040). The Impact of Regional Factors on the Growth of Innovative Enterprises and the Countermeasures.

(2) Heilongjiang Province Social Science Fund Project (17GLB016)

(3) Central University of Basic Scientific Research Business Project (HEUCFW170907)

\section{REFERENCES}

Aritaa, T., \& McCann, P. (2002). The spatial and hierarchical organization of Japanese and US multinational semiconductor firms. Journal of International Management, 8(1), 121-139.

Banai, R., \& Wakolbinger, T. (2011). A measure of regional influence with the analytic network process. SocioEconomic Planning Sciences, 45(4), 165-173.

Baptista, R., \& Mendonca, J. (2010). Proximity to knowledge sources and the location of knowledge-based start-ups, The Annals of Regional Science, 45(1), 5-29.

Beck, T., Demirguc-Kunt, A., \& Maksimovic, V. (2003). Financial and legal institutions and firm size. World Bank Policy Research Working Paper No. 2997.

Beck, T., Demirguc-Kunt, A., \& Maksimovic, V. (2006). The influence of financial and legal institutions on firm size. Journal of BankingEFinance, 30(11), 2995-3015.

Carlin, W., Schaffer, E. M., \& Seabrigt, P. (2010). A Framework for Cross-Country Comparisons of Public Infrastructure Constraints on Firm Growth. CEPR Discussion Paper No. DP7662.

Fan, J. (2007). Effect of regional soft milieu on enterprise competitiveness and its evaluation system. Science Research Management, 28(2), 99-104.

García-Pozoa, A., Campos-Soria, J. A., Sánchez-Ollero, J. L., \& Marchante-Lara, M. (2012). The regional wage gap in the Spanish hospitality sector based on a gender perspective. International Journal of Hospitality Management, 31(1), 266-275.

Helfat, C. E., \& Peteraf, M. A. (2003). The dynamic resource-based view: capability lifecycles. Strategic Management Journal, 24(10), 997-1010.

Hoover, E. M. (1984). An introduction to regional economics. McGraw-Hill Companies, 3rd edition.

Laeven, L. (2007). The quality of the legal system, firm ownership, and firm size. The Review of Economics and Statistics, 89(4), 601-614.

Lasch, F. (2011). Beyond the concept of human and social capital: the impact of the regional environment on hightech venturing. International Journal of Entrepreneurship and Small Business, 14(1), 56-76. 
Liu, P. H. (2016). Sociocultural Perspectives on the Internationalization of Research in Mathematics Education: A Survey Based on JRME, ESM, and MTL. Eurasia Journal of Mathematics, Science and Technology Education, 13(3), 911-927.

Lv, Y. B., Su, J. Q., \& Fu, Y., Research on growth drivers of small and middle sized enterprises in China: An empirical study on the North East areas of China. China Industrial Economics, 1, 14-22.

Malinowski, M. (2012). The interdependence of the regional environment state with the level of enterprise development. Management. The Journal of University of Zielona Góra, 16(2), 141-154.

Moore, J. F. (1996). The death of competition: leadership and strategy in the age of business ecosystems. New York: Harper Business.

Nelson, P. R., \& Winter, S. G. (1982). An evolutionary theory of economic change. Oxford University Press.

Nobel, R., \& Birkinshaw, J. (1998). Innovation in multinational corporations: control and communication patterns in international R\&D operations. Strategic Management Journal, 19(5), 479-496.

Pfeffer, J., \& Salancik, G. R. (1978). The external control of organizations: A resource dependence perspective. New York: Harper \& Row.

Rubalcaba, L., \& Gago, D. (2003). Regional concentration of innovative business services: Testing some explanatory factors at European regional level. The Service Industries Journal, 23(1), 77-94.

Saxenian, A. (1994). Regional advantage: Culture and competition in Silicon Valley and route 128. Cambridge: Harvard University Press.

Shleifer, A., \& Vishny, R. W. (1994). Politicians and firms. Quarterly Journal of Economics, 109(4), 995-1025.

Sorensen, J. B., \& Stuart, T. E. (2000). Aging, obsolescence, and organizational innovation. Administrative Science Quarterly, 45(1), 81-112.

Tang, J. (2006). Competition and innovation behavior. Research Policy, 35, 68-82.

Villaverde, J., \& Maza, A. (2012). Foreign direct investment in Spain: Regional distribution and determinants. International Business Review, 21(4), 722-733.

Wang, Y. P. (2016). A Study on Kinmen Resident's Perception of Tourism Development and Culture Heritage Impact. Eurasia Journal of Mathematics, Science E Technology Education, 12(12).

Xu, B., Li, X. D., Liu, H. F., \& Zhang, X. (2011). The Relationship between area factors and enterprise's performance: An empirical study based on 52 areas' manufacturing enterprises in China. Chinese Journal of Management, $8(6), 827-836$.

\section{http://www.ejmste.com}

